\title{
PENGARUH ELECTRONIC ROAD PRICING TERHADAP KONDISI LALU LINTAS RUAS JALAN KUNINGAN
}

\author{
Fernando Nathaniel $^{1}$ dan Najid $^{2}$ \\ ${ }^{1}$ Program Studi Sarjana Teknik Sipil, Universitas Tarumanagara, Jl. Letjen S. Parman No.1 Jakarta \\ fernando.325150010@stu.untar.ac.id \\ ${ }^{2}$ Program Studi Sarjana Teknik Sipil, Universitas Tarumanagara, Jl. Letjen S. Parman No.1 Jakarta \\ Najid2009@yahoo.com
}

Masuk: 05-07-2020, revisi: 04-09-2020, diterima untuk diterbitkan: 22-10-2020

\begin{abstract}
Electronic road pricing is a prepaid road which is used to decrease the traffic volume with using Electronic road pricing gate on the road that applied ERP and using In-Vehicle Unit device. The high number of vehicle volume at jakarta become one of the main reason of applying electronic road pricing. On this study will be discussed about the condition of Kuningan road traffic situation, this road is a main access for people especially to work and shopping. to analyze the vehicle volume will be using direct observation method to got the volume, velocity and intensiveness of the traffic. direct observation will be used to watch vehicle such as motorcycle, light vehicle and weight vehicle. with observation data we will get graphic about the connectivity between velocity and intensiveness that will be modified with questionnaire. questionnaire data will be spreaded out to get the percentage of decreased volume and estimated price for electronic road pricing. This study is expected to learn the electronic road pricing with most efficient price to decreased the vehicle volume at Kuningan road.
\end{abstract}

Keywords: Jakarta; Kuningan; Electronic Road Pricing

\begin{abstract}
ABSTRAK
Electronic Road Pricing adalah jalan berbayar yang digunakan untuk mengurangi kemacetan lalu lintas dengan cara memasangkan gate Electronic Road Pricing pada jalan yang akan dikenai ERP dan memasang In-Vehicle Unit. Tingginya volume kendaraan di Jakarta menjadi alasan utama diterapkan Electronic Road Pricing. Pada penelitian ini, dibahas mengenai kondisi lalu lintas jalan Kuningan, ruas jalan ini merupakan akses pengguna jalan untuk menuju perkantoran dan tempat perbelanjaan. Untuk menganalisa volume kendaraan akan digunakan metode observasi langsung untuk mendapatkan volume, kecepatan dan kepadatan lalu lintas. Observasi langsung dilakukan dengan memperhatikan kendaraan bermotor roda dua, kendaraan ringan dan kendaraan berat. Dengan data observasi akan didapat grafik hubungan antara kecepatan dan kedapatan yang akan dimodifikasi dengan data kuesioner. Data kuesioner disebar untuk mendapatkan persentase penurunan volume dan perkiraan harga Electronic Road Pricing untuk mengurangi volume lalu lintas. Diharapkan pada analisis penelitian ini dapat mengetahui biaya Electronic Road Pricing yang paling efisien untuk mengurangi volume kendaraan pada ruas jalan Kuningan.
\end{abstract}

Kata kunci: Jakarta; Kuningan; Electronic Road Pricing

\section{PENDAHULUAN}

Baiknya kinerja suatu jaringan jalan sangat mempengaruhi perkembangan suatu kota. Ketika jaringan jalan memiliki suatu kinerja jaringan jalan baik, banyak keuntungan yang didapatkan masyarakat. Keuntungan tersebut yang pada akhirnya meningkatkan penghasilan dan pendapatan daerah. Dengan lancarnya aktivitas pergerakan orang dan barang, maka secara langsung pendapatan ekonomi masyarakat akan meningkat. 
Menurut Sianipar \& Arbie (2018) jumlah penduduk yang tinggi ini sudah pasti menimbulkan pergerakan yang tinggi pula dapat terlihat dari jumlah berbagai jenis kendaraan yang terdaftar di berbagai kantor samsat. Kemacetan tentu saja tidak bisa dihindari di berbagai perkotaan, meledaknya jumlah kendaraan pribadi dan prilaku pengemudi kendaraan umum maupun pribadi yang rendah menjadi penyebab utama kemacetan lalu lintas dan angkutan umum dan pabila diterapkan ERP (Electronic Road Pricing).

Langkah yang biasanya ditempuh yaitu dengan meningkatkan efisiensi penggunaan ruang jalan, mengurangi angkutan yang tidak efisien dalam penggunaan ruang jalan. Untuk itu langkah yang dilakukan yakni dengan meningkatkan kapasitas infratruktur yang ada, membatasi dan mengendalikan penggunaan kendaraan pribadi serta mendorong penggunaan angkutan umum (Iskandar, 2012).

Pemprov DKI Jakarta berusaha mengurangi kemacetan yang ada di jakarta dengan membangun moda transportasi massal yang biasa disebut transjakarta. Bus Transjakarta ini bertujuan untuk meningkatkan jumlah perjalanan penumpang dengan transportasi Bus yang lebih aman dan nyaman bagi penumpang. Dan yang terpenting dengan diterapkannya sistem ini di Jakarta adalah untuk mengalihkan para pengguna kendaraan pribadi agar dapat berpindah menggunakan Bus Transjakarta sehingga dapat mengurangi kemacetan.

Untuk mengatasi masalah kemacetan butuh diberlakukannya kebijakan seperti 3 in 1, ganjil genap, under pass dan fly over. Dan salah satu metode yang akan diterapkan yaitu Electronic Road Pricing (ERP) yang akan menggantikan 3 in 1. Penerapan 3 in 1 dinilai memiliki kelemahan tersendiri seperti inkonsistensi penindakan pelanggaran aturan 3 in 1 , jumlah petugas yang tidak memadai dan kemunculan joki.

Dengan beralih dari kendaraan pribadi untuk menggunakan kendaraan umum, maka diharapkan polusi udara dan polusi suara yang ada di Jakarta juga dapat berkurang. Jika Bus Transjakarta memiliki kelebihan dibandingkan kendaraan umum lainnya, maka Bus Transjakarta juga memiliki kekurangan. Untuk itu, dilakukan studi dan penelitian untuk mengetahui kepuasan para pengguna sistem Transjakarta ini. Transjakarta sendiri memiliki beberapa masalah dan sering kali dikeluhkan oleh penggunanya. Masalah yang sering dikeluhkan oleh pengguna transjakarta dapat dikelompokkan menjadi beberapa jenis, yaitu:

- Bidang pengendalian yang terdiri dari keluhan untuk pramudi dan satgas dari transjakarta busway.

- Operasional Bus yang terdiri dari keluhan masalah headway dan masalah teknis.

- Operasional tiket yang terdiri dari keluhan untuk petugas tiket, mesin, untuk masalah teknis dan fisik.

- Bidang sarana dan prasarana seperti petugas, halte, dan keadaan cctv.

Masalah informasi berkaitan dengan arah rute dan tempat. Berdasarkan rincian masalah di atas menunjukkan bahwa secara keseluruhan pelayanan yang diberikan oleh transjakarta masih kurang baik, terbutki dengan masih banyaknya tingkat complain dari pelanggan transjakarta. (Putri \& Retnowati, 2017).

Road Pricing adalah pengenaan biaya secara langsung terhadap pengguna jalan karena melewati ruas jalan tertentu. Pada dasarnya terdapat dua tujuan dari penggunaan Road Pricing yaitu untuk menambah pendapatan suatu daerah atau negara, atau suatu sarana untuk mengatur penggunaan kendaraan agar tidak terjadi kemacetan. (Susantono, 2010)

Keberadaan ERP dapat menjadi salah satu alternatif solusi untuk mengurangi jumlah kendaraan pribadi, juga meningkatkan fasilitas kendaraan

Rumusan masalah yang akan dibahas adalah:

- Bagaimana pengaruh penerapan Electronic Road Pricing (ERP) terhadap permintaan pergerakan di jalan Rasuna Said (Koridor 6)?

- Bagaimana penerapan Electronic Road Pricing mempengaruhi kondisi lalu lintas di jalan Rasuna Said (Koridor 6)?

- Bagaimana karakteristik penumpang Transjakarta yang melalui jalan Rasuna Said (Koridor 6)?

Adapun beberapa tujuan dari penelitian ini adalah:

- Untuk mendapatkan model hubungan ERP permintaan pergerakan

- Analisis terhadap kondisi lalu lintas di jalan Rasuna said dengan adanya penerapan ERP.

- Untuk mendapatkan karakteristik penumpang Transjakarta pada Koridor 6 jalan Rasuna Said.

\section{BRT Transjakarta}

Bus Transjakarta umumnya disebut busway adalah sebuah sistem transportasi Bus Rapid Transit (BRT) pertama di Asia Tenggara dan Selatan, yang beroperasi sejak awal tahun 2004 di Jakarta. Bus transjakarta merupakan program unggulan pemerintah provinsi DKI Jakarta untuk pengembangan transportasi publik berbasis bus, juga merupakan 
pionir reformasi angkutan umum yang memprioritaskan kenyamanan, keamanan, keselamatan, dan keterjangkauan bagi masyarakat. Namun hingga kini masih terdapat faktor penyebab ketidakpuasan pengguna bus Transjakarta yang mengindikasikan bahwa manajemen Transjakarta masih perlu diperbaiki.

Berdasarkan data Badan Layanan Umum (BLU), Bus Transjakarta, tahun 2004 bus Transjakarta mampu mengangkut sebanyak 14,9 juta penumpang, tahun 2005 sebanyak 20.8 juta penumpang, tahun 2006 sebanyak 38.8 juta penumpang, tahun 2007 sebanyak 61.4 juta penumpang, dan tahun 2008 naik lagi ke angka 74.6 juta, tahun 2011 menjadi 114.7 juta, dan pada tahun 2019 bus Transjakarta melayani sebanyak 264.6 juta pelanggan. Naik 40 persen dibandingkan tahun sebelumnya, 2018 yang melayani 188.9 juta penumpang.

Prinsip diselanggarakannya sistem busway di Jakarta, tentu tak beda dengan penyelanggaraan sistem busway di negara-negara lain, yaitu think rail, use buses. Pelayanan yang prima kepada penumpang merupakan kunci keberhasilan sistem BRT, seperti halnya Transjakarta Busway. Dengan pelayanan yang bagus akan mendorong para pengguna kendaraan pribadi pindah ke Transjakarta Busway. Spesifikasi pelayanan yang dapat diberikan oleh sistem BRT berbeda dengan pelayanan yang diberikan oleh angkutan umum konvensional. Sistem Transjakarta Busway bertujuan untuk:

- Meningkatkan jumlah perjalanan penumpang dengan menyediakan keamanan.

- Menciptakan sistem trasnportasi dengan jalur eksklusif yang terpisah dari lalu lintas lain untuk meningkatkan aksesibilitas.

- Menciptakan sistem transportasi yang terjadwal..

- Meningkatkan kenyamanan dan keamanan bagi pengguna angkutan umum.

- Membangun dan meningkatkan sistem angkutan umum terintegrasi.

- Menciptakan sistem transportasi yang dapat meningkatkan efisiensi bagi operator bus.

- Membangun sistem pengumpulan pendapatan yang efektif.

Menurunnya kenyamanan di dalam Transjakarta terutama amat dirasakan oleh penumpang perempuan yang beberapa kali mengalami pelecehan seksual. Meskipun Transjakarta tidak steril dari tindak kriminalitas, tetap memiliki keunggulan dibandingkan dengan angkutan umum konvensional.

Data mengenai berbagai bentuk gangguan keamanan dan ketidaknyamanan yang terjadi di dalam bus Transjakarta selama kurun waktu 2010-2011 dapat dilihat pada tabel 1.

Tabel 1. data bentuk gangguan keamanan dan ketidaknyamanan di dalam bus Transjakarta

\begin{tabular}{cccc}
\hline No. & Jenis Kejadian & 2010 & 2011 \\
\hline 1. & Pelecehan seksual & 6 & 8 \\
2. & Penumpang terjatuh & 21 & 36 \\
3. & Penumpang terjepit & 9 & 24 \\
4. & Kehilangan barang & 17 & 13 \\
5. & Pemukulan satgas & 9 & 7 \\
6. & Penemuan barang & 89 & 216 \\
7. & Penangkapan pencopetan & 8 & 28 \\
\hline & TOTAL & 159 & 332 \\
\hline
\end{tabular}

Sumber: Paparan kepala BLU Transjakarta “ Refleksi 2011 - Rencana 2012” 7 Januari 2012

Berdasarkan data survei dari tabel di atas pada tahun 2010 - 2011 masih terdapat banyak gangguan keamanan dan ketidaknyamanan yang dirasakan oleh penumpang Transjakarta.

\section{Electronic Road Pricing}

Banyak negara yang telah menerapkan sistem ini. Singapura merupakan salah satu negara pertama sekali menerapkannya yang diawali pada September 1998 dengan Area Licencing Scheme (Gopinath \& Sarath, 2010). Pada awalnya merupakan suatu sistem dimana kendaraan yang masuk kawasan ALS diwajibkan berpenumpang 4 orang atau lebih. Jika kurang. Pengendara wajib membayar, untuk setiap kali masuk pada jam pembatasan lalu lintas diterapkan atau dapat dilakukan dengan pembayaran bulanan

Sistem ini kemudian diperbarui menjadi ERP pada tahun 1998 untuk mengatasi permasalahan pencatatan manual yang dilakukan oleh petugas serta memerlukan tenaga pencatatan yang besar. Pada sistem ini digunakan perangkat gerbang elektronik yang bisa menangkap sinyal yang dipancarkan dari unit atau instrument pada kendaraan yang dilengkapi dengan kartu prabayar. Unit atau instrument yang berada di dalam kendaraan ini, kemudian mengurangi nilai yang ada di dalam kartu prabayar tersebut setiap kali melewati gerbang elektronik.(Iskandar, 2012). 
Tujuan utama dari Electronic Road Pricing, yaitu mengurangi kemacetan, menjadi sumber pendapatan daerah, mengurangi dampak lingkungan, dan mendorong pengguna angkutan massal. ERP dapat menjadi pilihan solusi yang tepat guna mengurangi volume kendaraan di perkotaan. Namun penerapan ERP harus didukung dengan dukungan ketersediaan angkutan umum yang memadai sebagai pengganti angkutan pribadi. (Petrick \& Najid, 2018).

Cara kerja sistem Electronic Road Pricing (ERP) dimulai dengan instalasi in-vehicle unit (IU) di setiap mobil. IU ini berukuran sebesar buku kecil, dan ditenagai oleh baterai mobil. Alat ini dipasang secara permanen di bagian kanan bawah di kaca mobil depan menggunakan lem yang sangat kuat. Alat ini perlu saling berhadapan dengan antenna radio pada gate ERP untuk koneksi yang efektif.

IU diberi warna yang berbeda untuk jenis kendaraan yang berbeda karena biaya ERP yang berbeda-beda dan untuk mencegah IU untuk diubah-ubah. Kelas kendaraan terdiri dari mobil, taksi, sepeda motor, kendaraan ringan, kendaraan berat, bus, dan kendaraan darurat. Kendaraan darurat dibebaskan dari biaya ERP.

Sebelum berlaku dalam lalu lintas Electronic Road Pricing harus memenuhi syarat dan dasar hukum yang kuat untuk bisa diluncurkan. Dasar hukum yang dapat menopang Electronic Road Pricing yaitu:

1. Undang - undang Nomor 22 tahun 2009 tentang lalu lintas dan angkutan jalan pasal 133 ayat 3 Pembatasan lalu lintas dapat dilakukan dengan pengenaan retribusi pengendalian lalu lintas yang diperuntukan bagi peningkatan kinerja lalu lintas dan peningkatan pelayanan angkutan umum.

2. Rancangan Peraturan Pemerintah pasal 472 tahun 2010 tentang lalu lintas dan angkutan jalan

a. Pembatasan lalu lintas dapat dilakukan dengan pengenaan retribusi pengendalian lalu lintas;

b. Retribusi pengendalian lalu lintas adalah biaya tambahan yang harus dibayar oleh pengguna kendaraan perseorangan dan kendaraan barang akibat kemacetan yang disebabkannya;

c. Dana yang diperoleh dari retribusi pengendalian lalu lintas diperuntukkan bagi peningkatan kinerja lalu lintas dan pelayanan angkutan umum;

d. Ketentuan lebih lanjut tentang persyaratan penerapan pembatasan lalu lintas dengan pengenaan retribusi pengendalian lalu lintas diatur lebih lanjutdalam Peraturan Menteri yang bertanggung jawab dibidang sarana dan prasarana Lalu Lintasdan Angkutan Jalan di bidang Sarana dan Prasarana Lalu Lintas dan Angkutan Jalan dengan memperhatikan pendapat Menteri dibidang urusan dalam negeri

Peluang Electronic Road Pricing dalam undang - undang pajak daerah dan retribusi daerah nomor 28 tahun 2009 :

1. Retribusi Electronic Road Pricing tidak ditetapkan secara khusus dalam pasal 110 ayat 1, pasal 127 dan pasal 141 undang - undang pajak daerah dan retribusi daerah.

2. Jenis retribusi selain yang ditetapkan dalam pasal 110 ayat 1 , pasal 127 , dan pasal 141 sepanjang memenuhi kriteria tertentu dapat ditetapkan dengan peraturan pemerintah sebagai retribusi; (pasal 150)

3. Electronic Road Pricing dapat memenuhi kriteria sebagai retribusi jasa umum

4. Retribusi jasa umum = retribusi untuk jasa yang disediakan atau diberikan oleh pemerintah daerah untuk tujuan kepentingan dan kemanfaatan umum serta dapat dinikmati oleh orang pribadi atau badan; (pasal 1 ketentuan umum)

Kriteria retribusi jasa umum (Pasal 150 huruf a):

1. Retribusi jasa umum bersifat bukan pajak dan bersifat bukan retribusi jasa usaha atau retribusi perizinan tertentu;

2. Jasa yang bersangkutan merupakan kewenangan Daerah dalam rangka pelaksanaan desentralisasi;

3. Jasa tersebut memberi manfaat khusus bagi orang pribadi atau badan yang diharuskan membayar retribusi, disamping untuk melayani kepentingan dan kemanfaatan umum;

4. Retribusi tersebut hanya diberikan kepada orang pribadi atau badan yang membayar retribusi denganmemberikankeringanan bagi masyarakat yang tidak mampu;

5. Retribusi tidak bertentangan dengan kebijakan nasional mengenai penyelenggaraannya;

6. Retribusi dapat dipungut secara efektif dan efisien, serta merupakan salah satu sumber pendapatan daerah yang potensial;

7. Pemungutan retribusi memungkinkan penyediaan jasa tersebut dengan tingkat dan/atau kualitas pelayanan yang lebih baik.

\section{Lokasi Kuningan}

Jalan Kuningan (Rasuna Said) adalah nama salah satu jalan utama Jakarta dan juga merupakan pusat kawasan bisnis di Jakarta, bagian dari Segitiga Emas Jakarta, yang mencakup Jalan HR Rasuna Said, Jalan Jenderal Gatot Subroto, Jalan MH Thamrin, Jalan Jenderal Sudirman. Di Kuningan, Jakarta Selatan terdapat beberapa lokasi penting antara lain: Kantor Kedutaan, Besar Australia, Malaysia, Singapura, Polandia, Nigeria, India, Swiss, Rusia dan masih banyak lagi. Di sini juga terdapat gedung pusat kebudayaan Belanda, Erasmus Huis. Kawasan bisnis yang terkenal adalah Mega Kuningan, Rasuna Epicentrum. Jalan ini membentang sepanjang 4,9 kilometer. 
Kemacetan yang tidak terkendali dikarenakan jalur tersebut merupakan jalur pusat diantara daerah perkantoran dan perbelanjaan. Banyaknya kendaraan pribadi menjadi salah satu alasan macet di ruas jalan ini. Berdasarkan Pergub DKI Jakarta No 88 Tahun 2019 tentang perubahan atas peraturan gubernur nomor 155 tahun 2018 tentang pembatasan lalu lintas dengan sistem ganjil genap, gubernur menetapkan ruas jalan Kuningan (Rasuna Said) sebagai kawasan pembatas lalu lintas dengan sistem ganjil-genap.

\section{Metode Regresi Linear Berganda}

Regresi linier sederhana adalah salah satu metode analisi statistik yang membahas hubungan dari dua variabel yaitu satu variabel $\mathrm{X}$ dan satu variabel Y. Sebagai contoh, kita dapat melihat hubungan antara biaya periklanan (X) dan hasil penjualan (Y). Menurut perkiraan hubungan tersebut sangat mungkin, bisa jadi periklanan bukanlah satu-satunya penentu tinggi rendahnya hasil penjualan. Selain biaya periklanan bisa saja terdapat variabel lain yang dapat memengaruhi hasil penjualan. Sehingga bisa kita katakan bahwa ada banyak variabel $(X)$ yang akan memengaruhi variabel penjualan (Y). Maka dalam hal ini persamaan regresi linier berganda dapat digunakan untuk melihat hubungan dari satu variabel Y dan beberapa variabel X. Persamaann / rumus regresi linier berganda adalah sebagai berikut :

$$
\begin{aligned}
& \hat{Y}=b_{0}+b_{1} X_{1}+b_{2} X_{2}+\ldots . .+b_{\mathrm{k}} X_{k} \\
& \hat{Y}_{t}=b_{0}+b_{1} X_{1 i}+b_{2} X_{2 i}+\ldots . .+b_{k} X_{k i}
\end{aligned}
$$

dengan $\mathrm{i}=1,2, . . \mathrm{n}, \mathrm{Y}^{\wedge}=$ variabel terikat $\mathrm{Y}, \mathrm{X}=$ Variabel bebas, $\mathrm{b}_{0}=$ Konstanta, $\mathrm{b}_{\mathrm{i}}=$ Koefisien Penduga

\section{METODE PENELITIAN}

Pada penelitian ini, harus dibuat jalannya penelitian yang akan menjadi panduan dalam pelaksanaan penelitian agar penelitian dapat dijalankan dengan baik dan sistematis. Awal penelitian akan dilakukan pengamatan secara langsung di tempat, penyebaran kuesioner dengan kuesioner berjenis stated preference serta akan dilakukan pengamatan secara langsung di tempat, penyebaran kuesioner dengan ataupun wawancara langsung dengan narasumber. Angka penggunaan kendaraan akan diperhitungkan dan dibuat modelnya, lalu akan dibuat dalam grafik hubungan antara kecepatan, kepadatan, dan volume. Kemudian akan diidentifikasi masalah yang telah ada, lalu akan dilakukan pembuatan formulir survei yang akan di uji coba terlebih dahulu sebelum formulir survei sebagai kuesioner akhir.

Pengambilan data yang akan diambil yaitu data primer. Dimana data primer yaitu data hasil pengamatan dan hasil dari penyebaran kuesioner dan wawancara. Dari data primer ini akan dibuat model transportasinya yaitu dari data hasil pengamatan dan kemudian akan di modifikasi dengan menggunakan hasil data kuesioner yang akan dibuat kembali model transportasinya. Pengambilan data hasil pengamatan akan didapatkan kecepatan, kepadatan, dan volume kendaraan.

Pengambilan data kuesioner akan didapatkan jumlah pengguna Transjakarta yang sebelumnya menggunakan kendaraan pribadi dan kepuasan mereka terhadap pelayanan bus tersebut, serta pengaruh ERP terhadap permintaan penumpang Transjakarta.

Setelah menyelesaikan semua penelitian hingga akhir, dapat mendapatkan model lalu lintas serta hubungan kinerja lalu lintas dengan permintaan Transjakarta pada ruas jalan Sudirman-Thamrin. Metode yang akan digunakan dalam penelitian ini yaitu:

1. Studi literatur atau perpustakaan, dengan sumber seperti buku, jurnal- jurnal ilmiah yang ada hubungannya dengan yang akan dibahas, artikel - artikel yang ada di internet dan sebagainya.

2. Pendekatan metode survei.

3. Metode survei pada jalan yang ditinjau dengan cara memperhatikan jumlah kendaraan yang lewat dalam kurun waktu kurang lebih 1 jam.

4. Menganalisis data pengamatan dengan membuat model transportasi dan grafik hubungan antara kecepatan, kepadatan, dan volume.

5. Menganalisis data kuesioner.

\section{Metode pengumpulan data}

Survei yang akan dilakukan dengan cara pengamatan langsung ditempat adalah salah satu metode primer dalam penelitian ini yang mencangkup banyak hal seperti kapasitas jalan, kecepatan rata - rata, volume lalu lintas, dan tingkat kepuasan pelayanan Transjakarta diruas jalan Kuningan. Selain pengamatan secara langsung, survei ini didukung juga dengan survei wawancara atau kuesioner yang dimana hasil dari kuesioner ini akan digunakan untuk memodifikasi hasil survei pengamatan. 


\section{HASIL DAN PEMBAHASAN}

Pada bab ini akan menyajikan data yang diperoleh dari kuesioner responden yang disebar kepada responden pengguna jalan secara online. Data responden yang diambil sebanyak 50 orang. Data responden didapatkan dengan cara menyebarkan kuesioner.

Data aspek transportasi yang disurvei di lapangan adalah kondisi lalu lintas, kecepatan rata - rata lalu lintas, jalur, lajur, lebar jalan, lebar trotoar dan hambatan samping. Hasil dari survei ini untuk mendapatkan grafik hubungan antara kecepatan, kepadatan dan kapasitas lalu lintas.

Lokasi jalan untuk survei lalu lintas yaitu Jalan Kuningan ( Rasuna Said ). Lokasi ini dipilih karena merupakan salah satu lokasi yang memiliki angka kepadatan yang cukup tinggi dan dilewati oleh moda transportasi Umum seperti Transjakarta dan Mikrolet. Dengan adanya moda transportasi seperti Transjakarta dan Mikrolet ditargetkan untuk menjadi lokasiuntuk program Electronic Road Pricing (ERP) dan diharapkan angka kepadatan lalu lintas berkurang setelah program tersebut diberlakukan.

Observasi langsung yang dilakukan akan dibantu alat Manual Hand Tally dan penunjuk waktu digital yang digunakan untuk menghitung arus lalu lintas dan stop watch untuk menghitung kecepatan kendaraan. Kendaraan yang akan dihitung yaitu motor, mobil dan kendaraan besar. Untuk kecepatan rata - rata akan diambil dari data setiap kendaraan sebanyak 10 sampel dengan cara tiga pengamat yang berjarak 200 meter untuk setiap waktu arus lalu lintas dihitung. Observasi secara langsung akan dilakukan selama tiga waktu yaitu pada pagi pukul 06.00 - 08.00, pada siang pukul 12.00 - 14.00, dan pada sore pukul 17.00 - 19.00. Penghitungan kendaraan dan kecepatan rata - rata akan dilakukan selama 15 menit dengan durasi 2 jam. Selama penghitungan ini akan dilakukan oleh tiga orang yang bertugas untuk menghitung kendaraan motor, mobil dan kecepatan. Observasi akan dilakukan pada hari Senin, Selasa, Rabu atau Kamis karena pada hari tersebut kepadatan lalu lintas akan terlihat ketika jam sibuk.

Saat observasi langsung juga akan dilihat bagaimana keadaan lalu lintas pada daerah tersebut seperti hambatan samping. Hambatan samping yang akan dilihat yakni kendaraan tidak bermotor, kendaraan yang berhenti, kendaraan yang melawan arah, pejalan kaki yang menyebrang, dan kendaraan yang keluar masuk. Hambatan samping akan digunakan untuk mencari kapasitas lalu lintas.Dengan adanya moda transportasi seperti Transjakarta ditargetkan untuk menjadi lokasi untuk program Electronic Road Pricing (ERP) dan diharapkan angka kepadatan lalu lintas berkurang setelah program diberlakukan. Analisis ruas jalan Kuningan pada jam 07.00 - 08.00 dapat dilihat pada tabel 2.

Tabel 2. Analisis Ruas Jalan Kuningan, Rasuna Said (07.00- 08.00)

\begin{tabular}{|c|c|c|c|c|c|c|c|c|c|}
\hline \multirow{3}{*}{ Waktu } & \multicolumn{7}{|c|}{ Jumlah Kendaraar } & \multirow{2}{*}{$\begin{array}{c}\text { Volume } \\
\text { LL }\end{array}$} & \multirow[t]{2}{*}{$\begin{array}{l}\text { Kecepatan } \\
\text { Rata-Rata }\end{array}$} \\
\hline & $\begin{array}{l}\text { Jip, Pick } \\
U p \text {, Bus } \\
\text { Kecil, } \\
\text { Bus } \\
\text { Sedang }\end{array}$ & $\begin{array}{l}\text { Bus Kecil } \\
\text { dan Bus } \\
\text { Sedang } \\
\text { (Angkutan } \\
\text { Umum) }\end{array}$ & $\begin{array}{c}\text { Bus Besar } \\
\text { Wisata / } \\
\text { Karyawan } \\
\text { dan Truk }\end{array}$ & $\begin{array}{c}\text { Bus } \\
\text { Besar } \\
\text { dengan } \\
2 \text { gandar }\end{array}$ & $\begin{array}{c}\text { Truk } \\
\text { Besar dan } \\
\text { Bus Besar } \\
\text { dengan } 3\end{array}$ & $\begin{array}{l}\text { Sepeda } \\
\text { Motor }\end{array}$ & $\begin{array}{l}\text { Volume } \\
\text { LL }\end{array}$ & & \\
\hline & Gol I & Gol II & Gol III & Gol IV & Gol V & Gol VI & $\begin{array}{l}\text { Smp / } \\
15 \mathrm{mnt}\end{array}$ & $\begin{array}{c}\text { Smp / } \\
\text { jam }\end{array}$ & $\mathrm{Km} / \mathrm{jam}$ \\
\hline $07.00-07.15$ & 1.197 & 55 & 33 & 4 & 8 & 3.066 & $2.212,25$ & - & 30 \\
\hline $07.15-07.30$ & 1.404 & 60 & 34 & 6 & 9 & 2.628 & $2.333,5$ & - & 25 \\
\hline $07.30-07.45$ & 1.548 & 40 & 28 & 3 & 8 & 333 & $1.828,75$ & - & 20 \\
\hline $07.45-08.00$ & 1.206 & 28 & 44 & 3 & 7 & 1.488 & 1.783 & 8.158 & 26 \\
\hline
\end{tabular}


Analisis Ruas jalan Kuningan pada jam 08.00 - 09.00 dapat dilihat pada tabel 3.

Tabel 3. Analisis Ruas Jalan Kuningan, Rasuna Said (08.00- 09.00)

\begin{tabular}{|c|c|c|c|c|c|c|c|c|c|}
\hline \multirow{3}{*}{ Waktu } & \multicolumn{7}{|c|}{ Jumlah Kendaraar } & \multirow{2}{*}{$\begin{array}{c}\text { Volume } \\
\text { LL }\end{array}$} & \multirow{2}{*}{$\begin{array}{l}\text { Kecepatan } \\
\text { Rata-Rata }\end{array}$} \\
\hline & $\begin{array}{c}\text { Sedan, } \\
\text { Jip, Pick } \\
\text { Up, Bus } \\
\text { Kecil, } \\
\text { Bus } \\
\text { Sedang }\end{array}$ & $\begin{array}{l}\text { Bus Kecil } \\
\text { dan Bus } \\
\text { Sedang } \\
\text { (Angkutan } \\
\text { Umum) }\end{array}$ & $\begin{array}{c}\text { Bus Besar } \\
\text { Wisata / } \\
\text { Karyawan } \\
\text { dan Truk }\end{array}$ & $\begin{array}{c}\text { Bus } \\
\text { Besar } \\
\text { dengan } \\
2 \text { gandar }\end{array}$ & $\begin{array}{c}\text { Truk } \\
\text { Besar dan } \\
\text { Bus Besar } \\
\text { dengan } 3\end{array}$ & $\begin{array}{l}\text { Sepeda } \\
\text { Motor }\end{array}$ & $\begin{array}{l}\text { Volume } \\
\text { LL }\end{array}$ & & \\
\hline & Gol I & Gol II & Gol III & Gol IV & Gol V & Gol VI & $\begin{array}{l}\text { Smp / } \\
15 \mathrm{mnt}\end{array}$ & $\begin{array}{c}\text { Smp / } \\
\text { jam }\end{array}$ & $\mathrm{Km} / \mathrm{jam}$ \\
\hline $08.00-08.15$ & 1.584 & 36 & 35 & 4 & 7 & 1.401 & $2.139,5$ & 8.085 & 27 \\
\hline $08.15-08.30$ & 1.350 & 52 & 42 & 6 & 6 & 1.293 & $1.938,25$ & 7.689 & 28 \\
\hline $08.30-08.45$ & 1.323 & 24 & 37 & 4 & 13 & 1.185 & $1.814,25$ & 7.675 & 29 \\
\hline $08.45-09.00$ & 1.341 & 16 & 39 & 4 & 15 & 807 & $1.727,75$ & 7.620 & 29 \\
\hline
\end{tabular}

Analisis Ruas jalan Kuningan pada jam 12.00 - 13.00 dapat dilihat pada tabel 4.

Tabel 4. Analisis Ruas Jalan Kuningan, Rasuna Said (12.00- 13.00)

\begin{tabular}{|c|c|c|c|c|c|c|c|c|c|}
\hline \multirow{3}{*}{ Waktu } & \multicolumn{7}{|c|}{ Jumlah Kendaraar } & \multirow{2}{*}{$\begin{array}{c}\text { Volume } \\
\text { LL }\end{array}$} & \multirow[t]{2}{*}{$\begin{array}{l}\text { Kecepatan } \\
\text { Rata-Rata }\end{array}$} \\
\hline & $\begin{array}{l}\text { Sedan, } \\
\text { Jip, Pick } \\
\text { Up, Bus } \\
\text { Kecil, } \\
\text { Bus } \\
\text { Sedang } \\
\end{array}$ & $\begin{array}{c}\text { Bus Kecil } \\
\text { dan Bus } \\
\text { Sedang } \\
\text { (Angkutan } \\
\text { Umum) }\end{array}$ & $\begin{array}{c}\text { Bus Besar } \\
\text { Wisata / } \\
\text { Karyawan } \\
\text { dan Truk }\end{array}$ & $\begin{array}{c}\text { Bus } \\
\text { Besar } \\
\text { dengan } \\
2 \text { gandar }\end{array}$ & $\begin{array}{c}\text { Truk } \\
\text { Besar dan } \\
\text { Bus Besar } \\
\text { dengan } 3\end{array}$ & $\begin{array}{l}\text { Sepeda } \\
\text { Motor }\end{array}$ & $\begin{array}{l}\text { Volume } \\
\text { LL }\end{array}$ & & \\
\hline & Gol I & Gol II & Gol III & Gol IV & Gol V & Gol VI & $\begin{array}{l}\text { Smp / } \\
15 \mathrm{mnt}\end{array}$ & $\begin{array}{c}\text { Smp / } \\
\text { jam }\end{array}$ & $\mathrm{Km} / \mathrm{jam}$ \\
\hline $12.00-12.15$ & 1.089 & 32 & 4 & 5 & 13 & 693 & $1.397,25$ & - & 35 \\
\hline $12.15-12.30$ & 1.008 & 44 & 7 & 3 & 19 & 648 & $1.352,5$ & - & 37 \\
\hline $12.30-12.45$ & 927 & 68 & 44 & 4 & 30 & 597 & $1.441,25$ & - & 36 \\
\hline $12.45-13.00$ & 1.071 & 72 & 50 & 7 & 25 & 726 & $1.637,25$ & 5.829 & 33 \\
\hline
\end{tabular}

Analisis Ruas jalan Kuningan pada jam 13.00 - 14.00 dapat dilihat pada tabel 5.

Tabel 5. Analisis Ruas Jalan Kuningan, Rasuna Said (13.00- 14.00)

\begin{tabular}{|c|c|c|c|c|c|c|c|c|c|}
\hline \multirow{3}{*}{ Waktu } & \multicolumn{7}{|c|}{ Jumlah Kendaraar. } & \multirow{2}{*}{$\begin{array}{c}\text { Volume } \\
\text { LL }\end{array}$} & \multirow[t]{2}{*}{$\begin{array}{l}\text { Kecepatan } \\
\text { Rata-Rata }\end{array}$} \\
\hline & $\begin{array}{l}\text { Sedan, } \\
\text { Jip, Pick } \\
\text { Up, Bus } \\
\text { Kecil, } \\
\text { Bus } \\
\text { Sedang }\end{array}$ & $\begin{array}{l}\text { Bus Kecil } \\
\text { dan Bus } \\
\text { Sedang } \\
\text { (Angkutan } \\
\text { Umum) }\end{array}$ & $\begin{array}{c}\text { Bus Besar } \\
\text { Wisata / } \\
\text { Karyawan } \\
\text { dan Truk }\end{array}$ & $\begin{array}{c}\text { Bus } \\
\text { Besar } \\
\text { dengan } \\
2 \text { gandar }\end{array}$ & $\begin{array}{c}\text { Truk } \\
\text { Besar dan } \\
\text { Bus Besar } \\
\text { dengan } 3\end{array}$ & $\begin{array}{c}\text { Sepeda } \\
\text { Motor }\end{array}$ & $\begin{array}{l}\text { Volume } \\
\text { LL }\end{array}$ & & \\
\hline & Gol I & Gol II & Gol III & Gol IV & Gol V & Gol VI & $\begin{array}{l}\text { Smp / } \\
15 \mathrm{mnt}\end{array}$ & $\begin{array}{c}\text { Smp / } \\
\text { jam }\end{array}$ & $\mathrm{Km} / \mathrm{jam}$ \\
\hline $13.00-13.15$ & 1.251 & 52 & 51 & 5 & 52 & 717 & $1.830,25$ & 6.262 & 34 \\
\hline $13.15-13.30$ & 900 & 40 & 37 & 6 & 31 & 897 & $1.409,25$ & 6.318 & 34 \\
\hline $13.30-13.45$ & 1.080 & 32 & 39 & 3 & 33 & 741 & $1.532,75$ & 6.410 & 34 \\
\hline $13.45-14.00$ & 1.035 & 16 & 30 & 5 & 33 & 867 & $1.461,75$ & 6.234 & 34 \\
\hline
\end{tabular}


Analisis Ruas jalan Kuningan pada jam 16.00 - 17.00 dapat dilihat pada tabel 6.

Tabel 6. Analisis Ruas Jalan Kuningan, Rasuna Said (16.00- 17.00)

\begin{tabular}{|c|c|c|c|c|c|c|c|c|c|}
\hline \multirow{3}{*}{ Waktu } & \multicolumn{7}{|c|}{ Jumlah Kendaraar } & \multirow{2}{*}{$\begin{array}{c}\text { Volume } \\
\text { LL }\end{array}$} & \multirow{2}{*}{$\begin{array}{l}\text { Kecepatan } \\
\text { Rata-Rata }\end{array}$} \\
\hline & $\begin{array}{l}\text { Sedan, } \\
\text { Jip, Pick } \\
\text { Up, Bus } \\
\text { Kecil, } \\
\text { Bus } \\
\text { Sedang }\end{array}$ & $\begin{array}{l}\text { Bus Kecil } \\
\text { dan Bus } \\
\text { Sedang } \\
\text { (Angkutan } \\
\text { Umum) }\end{array}$ & $\begin{array}{c}\text { Bus Besar } \\
\text { Wisata / } \\
\text { Karyawan } \\
\text { dan Truk }\end{array}$ & $\begin{array}{c}\text { Bus } \\
\text { Besar } \\
\text { dengan } \\
2 \text { gandar }\end{array}$ & $\begin{array}{c}\text { Truk } \\
\text { Besar dan } \\
\text { Bus Besar } \\
\text { dengan } 3\end{array}$ & $\begin{array}{l}\text { Sepeda } \\
\text { Motor }\end{array}$ & $\begin{array}{l}\text { Volume } \\
\text { LL }\end{array}$ & & \\
\hline & Gol I & Gol II & Gol III & Gol IV & Gol V & Gol VI & $\begin{array}{l}\text { Smp / } \\
15 \mathrm{mnt}\end{array}$ & $\begin{array}{c}\text { Smp / } \\
\text { jam }\end{array}$ & $\mathrm{Km} / \mathrm{jam}$ \\
\hline $16.00-16.15$ & 1.116 & 48 & 40 & 3 & 32 & 2.037 & $1.932,75$ & - & 28 \\
\hline $16.15-16.30$ & 1.215 & 32 & 42 & 9 & 46 & 3.528 & $2.419,5$ & - & 27 \\
\hline $16.30-16.45$ & 1.161 & 24 & 39 & 10 & 33 & 3.072 & 2.194 & - & 27 \\
\hline $16.45-17.00$ & 1.170 & 28 & 51 & 7 & 38 & 3.432 & 2.338 & 8.884 & 25 \\
\hline
\end{tabular}

Analisis Ruas jalan Kuningan pada jam 17.00 - 18.00 dapat dilihat pada tabel 7.

Tabel 7. Analisis Ruas Jalan Kuningan, Rasuna Said (17.00- 18.00)

\begin{tabular}{|c|c|c|c|c|c|c|c|c|c|}
\hline \multirow{3}{*}{ Waktu } & \multicolumn{7}{|c|}{ Jumlah Kendaraar } & \multirow{2}{*}{$\begin{array}{c}\text { Volume } \\
\text { LL }\end{array}$} & \multirow{2}{*}{$\begin{array}{l}\text { Kecepatan } \\
\text { Rata-Rata }\end{array}$} \\
\hline & $\begin{array}{l}\text { Sedan, } \\
\text { Jip, Pick } \\
\text { Up, Bus } \\
\text { Kecil, } \\
\text { Bus } \\
\text { Sedang }\end{array}$ & $\begin{array}{l}\text { Bus Kecil } \\
\text { dan Bus } \\
\text { Sedang } \\
\text { (Angkutan } \\
\text { Umum) }\end{array}$ & $\begin{array}{l}\text { Bus Besar } \\
\text { Wisata / } \\
\text { Karyawan } \\
\text { dan Truk }\end{array}$ & $\begin{array}{c}\text { Bus } \\
\text { Besar } \\
\text { dengan } \\
2 \text { gandar }\end{array}$ & $\begin{array}{c}\text { Truk } \\
\text { Besar dan } \\
\text { Bus Besar } \\
\text { dengan } 3\end{array}$ & $\begin{array}{l}\text { Sepeda } \\
\text { Motor }\end{array}$ & $\begin{array}{l}\text { Volume } \\
\text { LL }\end{array}$ & & \\
\hline & Gol I & Gol II & Gol III & Gol IV & Gol V & Gol VI & $\begin{array}{l}\mathrm{Smp} / \\
15 \mathrm{mnt}\end{array}$ & $\begin{array}{c}\text { Smp / } \\
\text { jam }\end{array}$ & $\mathrm{Km} / \mathrm{jam}$ \\
\hline $17.00-17.15$ & 1.314 & 36 & 42 & 14 & 25 & 3.273 & $2.424,75$ & 9.376 & 20 \\
\hline $17.15-17.30$ & 1.134 & 36 & 44 & 4 & 14 & 4.635 & $2.537,75$ & 9.495 & 20 \\
\hline $17.30-17.45$ & 1.044 & 32 & 31 & 9 & 20 & 4.332 & 2.357 & 9.658 & 18 \\
\hline $17.45-18.00$ & 1.206 & 32 & 48 & 12 & 37 & 5.061 & $2.793,75$ & 10.113 & 15 \\
\hline
\end{tabular}

Hubungan kepadatan dan kecepatan di ruas jalan Kuningan dapat dilihat pada gambar 1.

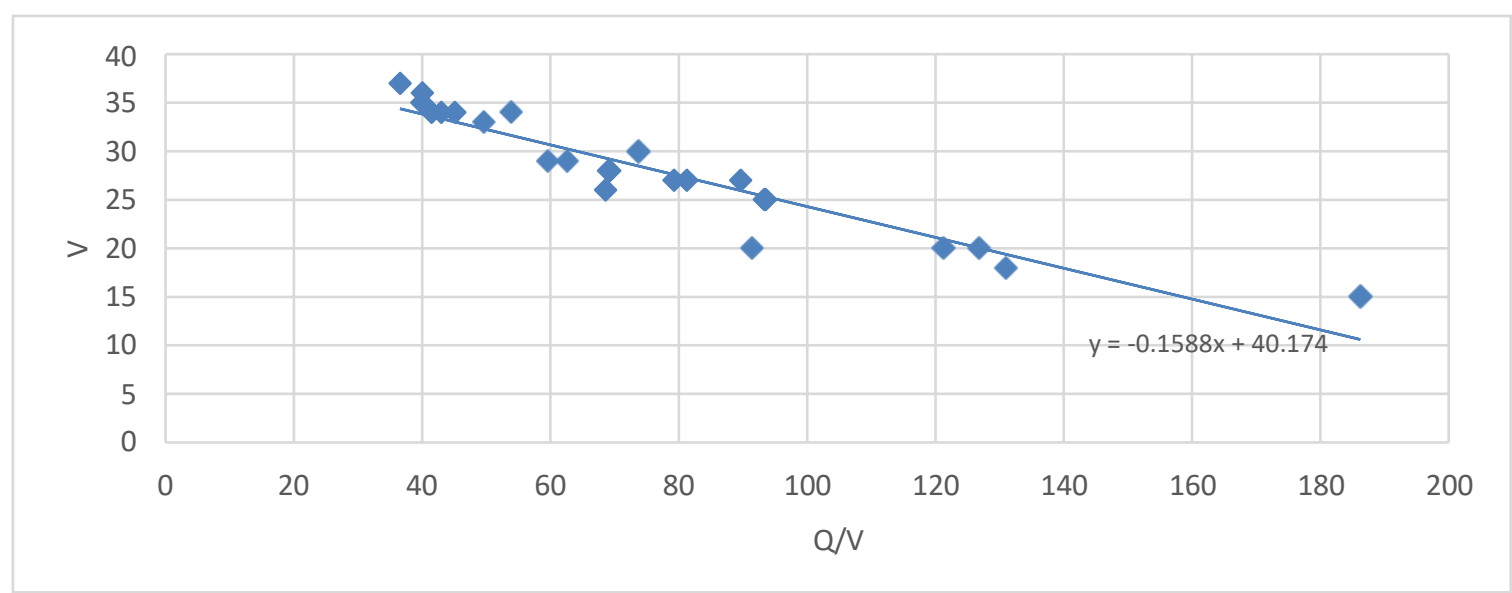

Gambar 1. Grafik hubungan kepadatan dan kecepatan pada Ruas Jalan Kuningan 
Untuk Data tabulasi pemilihan tarif Electronic Road Pricing dan waktu perjalanan dapat dilihat pada tabel 8.

Tabel 8. Tabulasi pemilihan tarif Electronic Road Pricing dan waktu perjalanan

\begin{tabular}{|c|c|c|c|c|c|c|}
\hline \multirow[b]{2}{*}{ No. } & \multicolumn{2}{|c|}{$\begin{array}{c}\text { Kondisi Perjalanan Setelah } \\
\text { Penerapan ERP }\end{array}$} & \multicolumn{4}{|c|}{ Pilihan (beri tanda X) } \\
\hline & $\begin{array}{l}\text { Tarif ERP } \\
\quad(\mathrm{Rp})\end{array}$ & $\begin{array}{c}\text { Waktu } \\
\text { perjalanan }\end{array}$ & $\begin{array}{l}\text { Pasti memilih } \\
\text { jalan }\end{array}$ & $\begin{array}{l}\text { Mungkin } \\
\text { memilih jalan }\end{array}$ & $\begin{array}{l}\text { Mungkin tidak } \\
\text { memilih jalan }\end{array}$ & $\begin{array}{l}\text { Tidak akan } \\
\text { memilih jalan }\end{array}$ \\
\hline 1 & 15.000 & $\begin{array}{l}\text { Lebih cepat } \\
10 \text { menit } \\
\text { Lebih cepat }\end{array}$ & 29 & 10 & 8 & 3 \\
\hline 2 & 30.000 & $\begin{array}{l}20 \text { menit } \\
\text { Lebih cepat }\end{array}$ & 15 & 20 & 11 & 4 \\
\hline 3 & 40.000 & $\begin{array}{l}30 \text { menit } \\
\text { Lebih cepat }\end{array}$ & 6 & 22 & 15 & 7 \\
\hline 4 & 50.000 & $\begin{array}{l}40 \text { menit } \\
\text { Lebih cepat }\end{array}$ & 5 & 13 & 21 & 11 \\
\hline 5 & 60.000 & $\begin{array}{l}45 \text { menit } \\
\text { Lebih cepat }\end{array}$ & 4 & 7 & 17 & 22 \\
\hline 6 & 65.000 & 50 menit & 6 & 7 & 11 & 26 \\
\hline
\end{tabular}

\section{Analisis data kuesioner}

Data hasil penyebaran kuesioner yang dikumpulkan akan dianalisis dengan menggunakan uji validitas dan akan dibantu dengan menggunakan program IBM SPSS versi 22.0. Dijalankan analisis tersebut dikarenakan untuk mengetahui hasil dari penyebaran kuesioner tersebut valid atau tidak.

Dari kuesioner yang telah dihitung menggunakan analisis statistik metode regresi didapatkan persamaan sebagai berikut:

$$
Y=-2,6195-0,0525 . X 1-0,1713 . X 2
$$

Variabel X1 menunjukkan tarif ERP sedangkan variabel X2 menunjukkan peningkatan pelayanan lalu lintas dengan memperkecil waktu perjalanan. Untuk permodelan dapat dilihat pada tabel 9.

Tabel 9. Pemodelan

\begin{tabular}{|c|c|c|c|}
\hline \multicolumn{4}{|c|}{$Y=-2,6195-0,0525 \cdot X 1-0,1713 \cdot X 2$} \\
\hline Y1 & $\underline{X 1}$ & $\underline{X} 2$ & $\underline{Y}$ \\
\hline$-2,6195$ & 15 & -10 & $-1,694$ \\
\hline$-2,6195$ & 30 & -20 & $-0,7685$ \\
\hline$-2,6195$ & 40 & -30 & 0,4195 \\
\hline$-2,6195$ & 50 & -40 & 1,6075 \\
\hline$-2,6195$ & 60 & -45 & 1,939 \\
\hline$-2,6195$ & 65 & -50 & 2,533 \\
\hline
\end{tabular}

Dari hasil yang diperhitungkan dan analisis yang telah dilakukan, maka diperoleh sebagai berikut:

1. Dari hasil jawaban data kuisioner dapat disimpulkan bahwa harga ERP Rp. 15.000 dan waktu perjalanan lebih cepat 10 menit merupakan waktu yang diminati oleh responden karena sebanyak 29 responden memilih waktu pelayanan tersebut.

2. Dari hasil analisis data dapat dilihat pada masing - masing ruas jalan mengalami kenaikan kecepatan dan volume kendaraan yang tinggi mengalami pengurangan.

3. Dari hasil pengujian model regresi linier dapat dilihat bahwa X1 dan X2 berpengaruh kepada Y, hal ini menandakan bahwa harga ERP Rp. 65.000 dan waktu perjalanan lebih cepat 50 menit merupakan harga yang efisien untuk meningkatkan efisiensi lalu lintas. 


\section{KESIMPULAN DAN SARAN}

\section{Kesimpulan}

Berdasarkan penelitian yang telah dilakukan, maka diperoleh kesimpulan sebagai berikut:

1. Dari hasil pengamatan langsung dapat diketahui bahwa peningkatan volume kendaraan terjadi pada pagi hari dan pada malam hari. Hal ini dikarenakan pengguna jalan lebih banyak digunakan saat jam kerja dan pulang kerja.

2. Dari hasil kuesioner yang telah disebar dapat diketahui bahwa responden lebih cenderung memilih harga Electronic Road Pricing pada kisaran harga Rp 15.000 sampai dengan Rp 30.000

3. Dari hasil analisis yang sudah dihitung dapat disimpulkan bahwa harga $\mathrm{Rp} 65.000$ merupakan harga yang sesuai untuk mengurangi kemacetan pada ruas jalan Kuningan (Rasuna Said) dan harga yang paling efektif untuk mengurangi kemacetan. Selain dari analisis, hasil kuesioner juga berpengaruh dalam kesimpulan ini dikarenakan semua responden tidak ada yang memilih untuk tidak melewati jalan bila ERP sudah diterapkan.

\section{Saran}

Berdasarkan penelitian yang telah dilakukan, maka terdapat beberapa saran sebagai berikut:

1. Penelitian yang sama perlu dilakukan pada ruas-ruas jalan yang saat ini diberlakukan ganjil genap.

2. Perlu melakukan survei lalu lintas satu hari penuh untuk mendapatkan lebih banyak variasi kondisi lalu lintas.

3. Kuisioner perlu disebar secara langsung dan tidak online untuk mendapatkan data yang lebih akurat.

\section{DAFTAR PUSTAKA}

Abubakar, Iskandar. “Manajemen Lalu Lintas”. Jakarta: TRASINDO Gastama Media. 2012

Petrick Dwi Saputra dan Najid. Pengendalian Penggunaan Kendaraan Pribadi Dengan Strategi Parkir dan ERP di Sudirman-Thamrin (DKI JAKARTA). Jurnal Mitra Teknik Sipil. Vol 1. No. 2 (November 2018): 9-18.

Putri Yulfa Rianti dan Retnowati WD Tuti. Kualitas Pelayanan Transjakarta Busway di DKI Jakarta. Jurnal Otonomi Daerah, Kebijakan Publik, dan Pengembangan Masyarakat. Vol 15. No. 2 (Juli 2017): 1693-3478.

Sianipar, Arbie. Analasis Potensi dan Kesiapan Penerapan Electronic Road Pricing di Wilayah Perkotaan. Warta Penelitian Perhubungan, November 2018, 85-100.

Gopinath, Sarath. Electronic Road Pricing: Experience \& Lessons From Singapore. SIM-air Working Paper. 2010. Series 33-2010.

Susantono, DR Bambang. Electronic Road Pricing (ERP) Salah Satu Solusi Masalah Kemacetan di Kota Jakarta, Buletin Tata Ruang, Disi September - Oktober. 2010 